九州大学学術情報リポジトリ

Kyushu University Institutional Repository

\title{
Characterization of high-velocity impact damage in CFRP laminates: Part II - prediction by smoothed particle hydrodynamics
}

Yashiro, Shigeki

Department of Mechanical Engineering, Shizuoka University

Ogi, Ke i ji

Graduate School of Science and Engineering, Ehime University

Yoshimura, Akinori

Advanced Composite Research Center, Japan Aerospace Exploration Agency (JAXA)

Sakaida, Yoshihisa

Department of Mechanical Engineering, Shizuoka University

ht tp://hdl. hand le. net/2324/4476061

出版情報 : Composites Part A: Applied Science and Manufacturing. 56, pp.308-318, 2013-05-02. Elsevier

バージョン：

権利関係 : 
Characterization of high-velocity impact damage in CFRP laminates: Part II prediction by smoothed particle hydrodynamics

Shigeki Yashiro ${ }^{\text {a, }}$, Keiji Ogi $^{\mathrm{b}}$, Akinori Yoshimura ${ }^{\mathrm{c}}$, and Yoshihisa Sakaida ${ }^{\mathrm{a}}$

${ }^{\text {a }}$ Department of Mechanical Engineering, Shizuoka University

3-5-1 Johoku, Naka-ku, Hamamatsu 432-8561, Japan

${ }^{\mathrm{b}}$ Graduate School of Science and Engineering, Ehime University

3 Bunkyo-cho, Matsuyama, Ehime 790-8577, Japan

${ }^{\mathrm{c}}$ Advanced Composite Research Center, Japan Aerospace Exploration Agency (JAXA)

6-13-1, Osawa, Mitaka, Tokyo 181-0015, Japan

* Corresponding author: Tel: +81-53-478-1026; Fax: +81-53-478-1026.

E-mail address: tsyashi@ipc.shizuoka.ac.jp (S. Yashiro)

\section{Abstract}

High-velocity impact damage in CFRP laminates was studied experimentally and numerically. Part I of this study observed and evaluated near-perforation damage in the laminates and characterized the damage pattern experimentally. Part II predicts the extension of high-velocity impact damage based on smoothed particle hydrodynamics (SPH), which facilitates the analysis of large deformations, contact, and separation of objects. A cross-ply laminate was divided into $0^{\circ}$ and $90^{\circ}$ layers, and virtual interlayer particles were inserted to express delamination. The damage patterns predicted on the surfaces and cross-sections agreed well with the experiments. The analyzed delamination shape was similar to that resulting from a low-velocity impact, consisting of pairs of fan-shaped delaminations symmetric about the impact point. Finally, the mechanisms of high-velocity impact damage in 
CFRP laminates are discussed based on the observations and numerical analyses.

Keywords: A. Polymer-matrix composites (PMCs); B. Impact behaviour; B. Delamination; C. Numerical analysis.

\section{Introduction}

Carbon fiber reinforced plastics (CFRPs) have good specific strength, specific modulus, and fatigue properties compared with conventional metals, so they have been applied to primary load-bearing structures such as wings and a fuselage in the latest airplanes. CFRPs have also been used in fan blades and fan cases of turbofan engines in recent years. One of the critical issues for these engines is reliability when subjected to high-velocity impact of foreign objects such as small stones, birds, and broken fan blades. Therefore, it is essential to clarify the extension mechanisms of high-velocity impact damage in composite laminates.

The ballistic limit energy and energy absorption during perforation have been investigated experimentally [1-6]. Several theories have also been proposed to predict the ballistic limit velocity based on the energy balance, considering the energy absorption due to damage extension $[3,7,8]$. The impact response of composite plates has been analyzed by the finiteelement method. Nandlall et al. [9] predicted damage in a GRP plate based on continuum damage mechanics. Gower et al. [10] analyzed the displacement of the back surface and delamination, which agreed with their experiment results. López-Puente et al. [11] predicted the projected damage area of thin carbon-epoxy woven laminates subjected to normal and oblique ballistic impacts. However, it has been pointed out that a complex contact algorithm and the remeshing and handling of largely deformed elements, in addition to adequate damage extension criteria, are necessary to accurately calculate the perforation by finite-element analysis $[12,13]$. 
In recent years, a number of numerical analyses of ballistic impacts on composite laminates have been presented using smoothed particle hydrodynamics (SPH), which is a meshless and fully Lagrangian method that facilitates calculations involving contact, large deformation, and separation. Chen et al. [14] introduced an orthotropic elastic-plastic constitutive law to the SPH and predicted the perforation characteristics of a quasi-isotropic laminate. Medina and Chen [15] implemented a one-parameter visco-plasticity composite material model and investigated the effects of the strain-rate dependency on the perforated area and residual strength within the hypervelocity range. Shintate and Sekine [16] proposed particle generation and particle merger techniques and successfully removed the unrealistic numerical fracture that frequently appears at the ballistic impact point using conventional SPH. Wicklein et al. [17] analyzed a hypervelocity impact on a CFRP-Al honeycomb sandwich structure and compared the damage states between predictions and experiments.

Although previous research on high-velocity and hypervelocity impacts focused on the perforation characteristics and the ballistic limit, the generation and extension of individual damage in plies and ply interfaces have not been discussed in detail. In order to estimate the energy absorption due to damage extension, it is valuable to investigate the complex damage extension mechanisms using numerical analyses.

This study thus characterizes the high-velocity impact damage in CFRP laminates to clarify the damage extension mechanisms. To this end, we focus on impact damage near the perforation. This study consists of two parts. Part I [18] conducted high-velocity impact tests for unidirectional laminates, two types of cross-ply laminates, and quasi-isotropic laminates, and observed their damage states. Part II analyzes the high-velocity impact on CFRP cross-ply laminates based on SPH and predicts the extension of impact damage considering detailed damage modes. Our experiments [18] are summarized in Section 2 for completeness. The 
analytical model and damage criteria are provided in Section 3. Finally, Section 4 presents the numerical results and discusses the mechanisms of the damage extension.

\section{Summary of high-velocity impact tests}

Our experiment [18] tested CFRP laminates with four stacking sequences; this section summarizes the results of cross-ply $\left[04 / 90_{4}\right]$ s laminates as a typical case. Square specimens were prepared from CFRP prepreg sheets (T700S/\#2521R, Toray), with dimensions of $55 \mathrm{~mm}$ on a side and $1.6 \mathrm{~mm}$ thick. Here, the fiber direction in the top and bottom plies was defined as the $0^{\circ}$ direction. A high-velocity impact testing machine with an electric-heat gun was used, and the projectile was a steel ball with a diameter of $1.5 \mathrm{~mm}$ (14.2 $\mathrm{mg}$ in mass). The tested velocity was 200 to $1200 \mathrm{~m} / \mathrm{s}$. The size of the fixture jig was $50 \mathrm{~mm}$ on a side, and there was no supporting plate on the back surface. The laminate thus bent freely upon impact.

Figure 1 depicts the damage states on the front surface and the back surface. A crater was generated due to the impact, and splits extended from both edges of the crater on the front surfaces of all of the specimens. Matrix cracks appeared on the back surfaces, even at low velocity $(344 \mathrm{~m} / \mathrm{s})$, and fiber breaks and peeled ply were observed with a higher impact velocity. The damaged area of both surfaces increased with increasing velocity, but the damage pattern was identical regardless of the velocity.

Figure 2 depicts the damage just beneath the impact point. Two cross-sections including the impact point were observed as depicted in Fig. 2a. One is a cross-section normal to the fiber direction of the $0^{\circ}$ ply ( $\mathrm{N}$-section); the other is a cross-section parallel to that direction (Psection). A crush zone (crater), extensive fiber breaks in the middle $90^{\circ}$ ply, delaminations, and matrix cracks in the bottom $0^{\circ}$ ply were observed in the N-section (Fig. 2b). A crater with fiber breaks, catastrophic ply failure in the $90^{\circ}$ ply, oblique matrix cracks, and delamination 
were observed in the P-section (Fig. 2c). The lower $0^{\circ}$ ply was peeled off because of significant delamination in the P-section. Considering the observations of the two crosssections, the catastrophic ply failure zone included extensive fiber breaks, matrix crushing and cracking, and delaminations. Oblique matrix cracks were generated outside the ply failure zone in the $90^{\circ}$ ply, and their tips were connected to delamination areas. The delamination at the $0^{\circ} / 90^{\circ}$ ply interfaces extended far more in the $0^{\circ}$ direction than in the $90^{\circ}$ direction.

Soft X-ray photographs are presented in Fig. 3. Delaminations were generated near the impact point. The delamination at the upper $0^{\circ} / 90^{\circ}$ interface extended from the tips of the matrix cracks in the top $0^{\circ}$ ply to the transverse $\left(90^{\circ}\right)$ direction. The lower $90^{\circ} / 0^{\circ}$ interface delaminated along the matrix crack in the bottom $0^{\circ}$ ply. These delaminations were symmetric with respect to the impact point, and this pattern was similar to that observed in the laminate subjected to low-velocity impact. A higher velocity induced elongated delamination accompanied by matrix cracks in the bottom ply.

\section{Analysis}

In order to characterize the extension of high-velocity impact damage in composite laminates, this study conducted three-dimensional analysis based on SPH, which is a meshfree particle-simulation method that facilitates calculating large deformation and separation. The fundamental equations of SPH for isotropic elastic solids are provided in the references $[16,19]$. The motion of the steel projectile was analyzed based on these equations. This section introduces the analytical model, the constitutive equation of orthotropic fiberreinforced composites, and the material failure model applied in this simulation. This study focuses on near-perforation damages, not on perforation characteristics discussed in Ref. [16]. This analysis then requires damage criterion considering the orthotropic nature of each ply 
and material degradation rules considering microscopic damage and stress transfer mechanisms. A self-made code was used in this study.

\subsection{Analytical model}

Before conducting the damage extension simulation, the model size was first investigated by using a large particle $(0.16 \mathrm{~mm})$, and two models were prepared. One was a full-scale quarter model (the target was $25.0 \mathrm{~mm}$ long, $25.0 \mathrm{~mm}$ wide, and $1.6 \mathrm{~mm}$ thick), and the other was a small quarter model (the target was $7.2 \mathrm{~mm}$ long, $4.8 \mathrm{~mm}$ wide, and $1.6 \mathrm{~mm}$ thick). The edges of the target were fixed in the full-scale model, while the target was not fixed in the small model. The initial velocity of the projectile was $600 \mathrm{~m} / \mathrm{s}$. It was found that the pattern and size of damage generated in the surfaces and cross-sections were almost identical among these two models. They were also identical to the results of the fine model that will be discussed in Section 4. This is because the target exhibited a significant local deformation, and because damage was not generated by reflected stress waves. These test simulations indicated that the damage extension depended solely on the state near the impact point regardless of the areal size of the target. This result was also demonstrated experimentally [20]. The local deformation was prominent within the range of $5 \mathrm{~mm}$ from the impact point at the impact velocity of $600 \mathrm{~m} / \mathrm{s}$. Therefore, if the model size is larger enough than this size, there will be no influence of the model size on the damage growth.

The analytical model used in this study is illustrated in Fig. 4. A quarter of the whole system was modeled considering the symmetry, and the CFRP target was $9.0 \mathrm{~mm}$ long, 9.0 $\mathrm{mm}$ wide, and $1.6 \mathrm{~mm}$ thick; the diameter of the projectile was $1.5 \mathrm{~mm}$. The initial spacing between neighboring particles was $0.089 \mathrm{~mm}$, and there were 184198 particles. Virtual interlaminar layers were inserted into the $0^{\circ} / 90^{\circ}$ ply interfaces to represent delamination. The 
modulus of this layer should be small so that it will have no influence on the mechanism of stress transfer. The laminate was not fixed, and the projectile collided vertically with the laminate at a prescribed initial velocity.

A CFRP lamina was considered as an orthotropic elastic material in this analysis. Table 1 lists the properties of the CFRP unidirectional lamina. The stress rate $\dot{\sigma}_{i j}$ is calculated from the deformation rate $\dot{\varepsilon}_{i j}$ as

$$
\{\dot{\varepsilon}\}=[\mathbf{S}]\{\dot{\sigma}\},
$$

where $\{\dot{\varepsilon}\}^{T}=\left\{\dot{\varepsilon}_{11}, \dot{\varepsilon}_{22}, \dot{\varepsilon}_{33}, \dot{\gamma}_{23}, \dot{\gamma}_{31}, \dot{\gamma}_{12}\right\}^{T}$ and $\{\dot{\sigma}\}^{T}=\left\{\dot{\sigma}_{11}, \dot{\sigma}_{22}, \dot{\sigma}_{33}, \dot{\sigma}_{23}, \dot{\sigma}_{31}, \dot{\sigma}_{12}\right\}^{T}$. Subscripts 1, 2 , and 3 denote the fiber direction, the transverse direction, and the through-the-thickness direction. Matrix $[\mathbf{S}]$ is the compliance matrix, and its components are represented as

$$
\begin{aligned}
& S_{11}=\frac{1}{E_{1}}, \quad S_{22}=S_{33}=\frac{1}{E_{2}}, \quad S_{12}=S_{13}=-\frac{v_{12}}{E_{1}}, \quad S_{23}=-\frac{v_{23}}{E_{2}}, \\
& S_{44}=\frac{1}{G_{23}}, \quad S_{55}=S_{66}=\frac{1}{G_{12}}
\end{aligned}
$$

where $E, G$, and $v$ are the Young's modulus, shear modulus, and Poisson's ratio. The Young's modulus and Poisson's ratio of the interlaminar layer was $2.65 \mathrm{GPa}$ and 0.36 assuming the epoxy resin. The stresses in the interlaminar particles are calculated by the same procedure as the CFRP particles. Equations (1) and (2) assume linear elastic relation between the stress and the strain, but in general, a CFRP unidirectional lamina has nonlinearity in the in-plane shear deformation. The influence of the nonlinear shear behavior was discussed in Appendix.

The stresses of the steel projectile were calculated based on the constitutive equations of isotropic materials [16]. Table 2 lists the material properties of the steel projectile.

\subsection{Material failure model for composite laminates}

This analysis applied modified Chang-Chang failure criteria with a delamination criterion 
[21] to the CFRP laminate to identify the damage mode in each particle. The following equations are evaluated at every time integration step.

1. Fiber failure

$$
\left(\frac{\sigma_{11}}{F_{L}}\right)^{2}+\left(\frac{\sigma_{12}^{2}+\sigma_{13}^{2}}{F_{L T f}^{2}}\right) \geq 1
$$

$F$ denotes the strength, subscripts $L$ and $T$ represent the fiber longitudinal direction and the transverse direction, and the following lower-case subscripts represent the fracture mode: $t$ is tensile failure, $c$ is compressive failure, and $s$ is shear failure. Tensile strength $F_{L t}$ is used as the strength in the longitudinal direction, $F_{L}$, when $\sigma_{11} \geq 0$, and the compressive strength $F_{L c}$ is used when $\sigma_{11}<0 . F_{L T f}$ is the shear strength involving fiber failure.

2. Matrix cracking

$$
\left(\frac{\sigma_{22}}{F_{T t}}\right)^{2}+\left(\frac{\sigma_{12}}{F_{L T S}}\right)^{2}+\left(\frac{\sigma_{23}}{F_{T T S}}\right)^{2} \geq 1, \text { if } \sigma_{22} \geq 0
$$

3. Matrix crushing

$$
\frac{1}{4}\left(\frac{-\sigma_{22}}{F_{L T S}}\right)^{2}+\frac{1}{4} \frac{F_{T c}{ }^{2} \sigma_{22}}{F_{L T S}{ }^{2} F_{T c}}-\frac{\sigma_{22}}{F_{T c}}+\left(\frac{\sigma_{12}}{F_{L T S}}\right)^{2} \geq 1, \text { if } \sigma_{22}<0
$$

4. Delamination

$$
\left(\frac{\sigma_{33}}{F_{T t}}\right)^{2}+\left(\frac{\sigma_{23}}{F_{T T S}}\right)^{2}+\left(\frac{\sigma_{31}}{F_{L T S}}\right)^{2} \geq 1
$$

The first term of the left-hand side is removed if $\sigma_{33}<0$.

Table 3 lists the strengths used in this study [16,22,23], while some values are slightly fitted to the experiments. The strengths for the interlaminar layer are typical values assuming the epoxy resin. Equation (6) is applied only to particles in the interlaminar layer to judge delamination extension.

If a particle was assumed to break, the stiffness and stresses in the particle were degraded, considering the stiffness reduction due to the damage and the mechanism of stress transfer. 
Table 4 lists the particle degradation rule used in this analysis. When one of the failure criteria was satisfied, the stress components related to the damage mode were set to zero [21], and the relevant stiffness was updated to the degraded value. The degradation factors should be zero at a crack surface, but nonzero values were applied considering stress recovery in a particle; these values were fitted to the experiments. In order to transfer compressive stresses, all broken particles were not removed, and slightly large degradation factors were used in the compression failure modes.

\section{Analytical results and discussion}

Figure 5 depicts the damage patterns on the front surface and the back surface, in which the whole target dimensions are depicted for easy understanding. Matrix cracking denotes the cracks due to tensile transverse stresses and shear stresses, and matrix crushing indicates the matrix failure by compression and shear. A crater with fiber breaks was formed on the front surface, and matrix crushing and matrix cracking extended in the fiber direction. The straight matrix crushing and cracking appeared as the multiple splits observed in Fig. 1, although the crack lengths differed. Only a single crack was predicted on the back surface at $344 \mathrm{~m} / \mathrm{s}$, and this corresponds to the barely visible damage in Fig. 1. Multiple matrix cracks and fiber breaks were generated on the back surface at higher velocities. Small fiber breaks occurred beneath the impact point at $618 \mathrm{~m} / \mathrm{s}$, and the fiber breaks increased with increasing velocity. These damage patterns on the front and back surfaces agreed well with the experiment. Unrealistic oblique cracks appeared on the back surface at $885 \mathrm{~m} / \mathrm{s}$, possibly due to insufficient damage criterion.

Figure 6a depicts the damage extension in the $\mathrm{N}$-section, where the projectile was removed in this figure. Matrix cracking and crushing in the top $0^{\circ}$ ply (A) reached the $0^{\circ} / 90^{\circ}$ ply 
interface, and delamination (B) was generated from those tips at $0.4 \mu$ s after the collision. A crater zone was formed by the matrix failure. Severe matrix damage (C) and fiber compressive failure (D) occurred in the middle $90^{\circ}$ ply after $0.8 \mu \mathrm{s}$, and the lower ply interface also delaminated. Matrix cracking (E), which appeared as splits on the front surface, occurred on the side of the crater at $2.0 \mu \mathrm{s}$. The number of matrix cracks on the top $0^{\circ}$ ply increased as time advanced. Transverse cracks (F) was also predicted in the bottom $0^{\circ}$ ply, corresponding to the multiple splits observed on the back surface (Fig. 1).

Figure $6 \mathrm{~b}$ depicts the predicted damage extension in the P-section. The top $0^{\circ}$ ply suffered matrix failure (A) and fiber breaks $(G)$ near the impact point, and a crater was formed. The $0^{\circ} / 90^{\circ}$ ply interface was then delaminated (B), and a matrix cracking and crushing zone (C) appeared in the $90^{\circ}$ ply. This damage pattern agreed with the observation (Fig. 2). Greater delamination size was predicted in the P-section than in the $\mathrm{N}$-section; this result also coincided with the observation. Although well-defined cone cracks were not predicted in the $90^{\circ}$ ply, matrix cracking did occur outside the crushing zone. These matrix cracks correspond to the cone cracks observed in Fig. 2. A transverse crack (F) appeared just beneath the impact point in the bottom $0^{\circ}$ ply, and this damage could be observed on the back surface (Fig. 1).

Both normal stresses and shear stresses are considered in the damage criteria (Eqs. (3)-(6)) under a multiaxial stress condition. The contribution of the shear terms to damage is plotted in Fig. 7 to determine the major cause of damage generation. The color indicates the magnitude of the shear term(s) in Eqs. (3)-(6) at breakage of each particle. It was found that little contribution of the shear stress was observed except for delaminations in both cross-sections. Normal stress due to indentation and bending was therefore the major factor of the highvelocity impact damage. In the P-section, high contribution of shear stresses was observed in the matrix cracking region outside the crushing zone of the $90^{\circ}$ ply, i.e., cone cracking region. 
The projection of damaged particles in the $z$-direction is depicted in Fig. 8a for comparison with the soft X-ray photographs. Delaminations (B) were generated near the crater $(A, G)$ along the matrix crack $(\mathrm{F})$ in the bottom $0^{\circ}$ ply, and this pattern agreed well with the observation (Fig. 3). Figures $9 \mathrm{~b}$ and 9c depict the delamination at the upper and lower ply interfaces. The upper delamination extended more in the $90^{\circ}$ direction than did the lower delamination, and this trend was also observed in the experiment. This delamination became peanut-shaped with increasing velocity, which was observed in the experiment, including in the low-velocity impact.

Based on the experiments (Ref. [18] and Figs. 1-3) and the above analyses, the extension mechanisms of high-velocity impact damage in CFRP laminates are estimated as follows (Fig. 9). (1) Fiber breaks and matrix crushing induced by the compressive stress and the local bending deformation are generated just beneath the impact point in the top $0^{\circ}$ ply, and these form a crater. (2) Matrix crushing and cracking occurs from both edges of the crater in the top ply, and these cracks appear as splits on the front surface. Shear stresses contribute less to these cracks than did normal stresses, and thus the compressive stress due to the impact and the accompanying local bending deformation are the major causes of matrix damage in the top ply. (3) After the crater zone reaches the upper ply interface, delamination occurs mainly in the shear mode, since compressive stress is generated in the through-the-thickness direction by the impact. The delaminations extend in a symmetric fan shape from the impact point, which can be observed in the low-velocity impact. The delamination area will be governed by the matrix cracks in the plies adjacent to the interface. (4) The middle plies fail catastrophically. This ply failure consists of fiber breaks, matrix cracking, and matrix crushing. (5) The ply interfaces are delaminated due to the neighboring matrix damage. Pairs of fanshaped delaminations symmetric about the impact point extend at each interface, similarly to 
those of the top interface. (6) Fibers in the bottom $0^{\circ}$ ply break beneath the impact point due to local bending deformation. The bending deformation also induces multiple matrix cracks in the bottom ply, which appear as splits in the back surface. The fiber breaks and matrix cracks accelerate the delamination extension at the lowest ply interface along the matrix cracks. The damage patterns observed in the other stacking sequences were similar to that of the cross-ply laminate (Figs. 1-3) [18], and therefore these damage-extension mechanisms will be identical among all of the stacking sequences.

\section{Conclusions}

This study experimentally and numerically investigated mechanisms of the extension of high-velocity impact damage in CFRP laminates and consisted of two parts. Part I [18] conducted high-velocity impact tests for CFRP laminates with four stacking sequences, and observed near-perforation damage states. Part II predicted the extension of high-velocity impact damage in a cross-ply laminate using smoothed particle hydrodynamics (SPH). The laminate was modeled by particles, and interlaminar particles were inserted into the $0^{\circ} / 90^{\circ}$ layer interface to represent delamination. Damage in a particle was judged by modified Chang-Chang criteria, and a material degradation rule was applied to the stiffness and stress in the damaged particle. Three-dimensional simulation was conducted, and the impactdamage extension was analyzed.

The high-velocity impact damage predicted by SPH included a crater and matrix cracking/crushing in the top ply, catastrophic failure of the middle plies, and fiber breaks and matrix cracking in the bottom ply. The predicted damage patterns agreed well with those observed on the front and back surfaces and cross-sections beneath the impact point. The crater and the catastrophic ply failure consisted of significant fiber breaks and matrix failure 
induced by indentation and local bending. Pairs of fan-shaped delaminations symmetric about the impact point were predicted, and this pattern coincided with the observation. It was found that the delamination generated by high-velocity impact was similar to that observed in laminates impacted at a low velocity. Finally, the extension mechanisms of the high-velocity impact damage were estimated based on the observations of near-perforation damage and corresponding analyses of impact-damage extension.

\section{Acknowledgment}

S. Y. acknowledges the support of the Ministry of Education, Culture, Sports, Science and Technology of Japan under Grants-in-Aid for Scientific Research (Nos. 21360417 and 22760524).

\section{Appendix 1. Influence of nonlinear shear behavior}

This section investigated the influence of the nonlinear shear behavior on the high-velocity impact damage. The analytical model depicted in Fig. 4 was used. An empirical equation representing the nonlinear in-plane shear stress-strain relation is given by

$$
\tau=71.41+3.66 \gamma-91.52 e^{-\gamma}+20.11 e^{-2 \gamma},
$$

where $\tau$ is the shear stress in MPa and $\gamma$ is the engineering shear strain in percent [24]. This equation was transformed to the time differentiation form and was applied to the relation between $\dot{\tau}_{12}\left(\dot{\tau}_{31}\right)$ and $\dot{\gamma}_{12}\left(\dot{\gamma}_{31}\right)$. If the absolute value of the shear strain was smaller than the maximum value, the initial stiffness of Eq. (7) was given as the tangent stiffness. Here, the initial stiffness was almost the same as the in-plane shear modulus of the linear elastic analysis. The nonlinearity in out-of-plane shear was ignored, since its nonlinear effect would be much smaller than that of in-plane shear. 
The damage pattern taking the nonlinearity into account was compared with that of the linear elastic analysis at the impact velocity of $600 \mathrm{~m} / \mathrm{s}$. Figure 10 depicts the damage states on the front and back surfaces. A crater and multiple splits on the front surface, as well as the matrix cracks on the back surface, were generated regardless of considering the nonlinearity. Figure 11 presents the damage states on the N-section and the P-section at $4.0 \mu$ s after collision. The target with the nonlinear material properties exhibited greater out-of-plane deformation than in the linear elastic analysis, since the nonlinearity yielded greater shear strain. This led to extensive damaged region in the nonlinear analysis. However, in both analyses, the damage in the cross-section included a crater on the top ply, the catastrophic ply failure consisting of matrix damage and fiber breaks, the matrix crack in the bottom ply, and delamination at ply interfaces. Figure 12 depicts delamination shape. Although the properties of the interlaminar layer were identical, greater delamination was generated when considering the nonlinearity, because the large out-of-plane deformation caused severe interlayer shear deformation. The shape of the delamination with the nonlinear shear behavior did not agree with the observations (Fig. 3). Thus, the influence of the nonlinear shear behavior on the mechanisms of high-velocity impact damage was small. The rate dependency of the shear stress-strain relation will lead to this conclusion. In general, the yield stress increases, and the failure strain decreases with increasing strain rate. Therefore, the simulation with linear elastic material properties, in which the failure strain was small, provided good predictions, although more verification will be needed to figure out the nonlinear shear effect including the rate dependency.

\section{Reference}

[1] López-Puente J, Zaera R, Navarro C. The effect of low temperatures on the intermediate 
and high velocity impact response of CFRPs. Composites Part B 2002; 33:559-566.

[2] Tanabe Y, Aoki M, Fujii K, Kasano H, Yasuda E. Fracture behavior of CFRPs impacted by relatively high-velocity steel sphere. Int J Impact Eng 2003; 28:627-642.

[3] Caprino G, Lopresto V, Santoro D. Ballistic impact behaviour of stitched graphite/epoxy laminates. Compos Sci Technol 2007; 67:325-335.

[4] Hazell PJ, Kister G, Stennett C, Bourque P, Cooper G. Normal and oblique penetration of woven CFRP laminates by a high velocity steel sphere. Compos Part A 2008; 39:866874.

[5] Hazell PJ, Cowie A, Kister G, Stennett C, Cooper GA. Penetration of a woven CFRP laminate by a high velocity steel sphere impacting at velocities up to $1875 \mathrm{~m} / \mathrm{s}$. Int $\mathrm{J}$ Impact Eng 2009; 36:1136-1142.

[6] Appleby-Thomas GJ, Hazell PJ, Dahini G. On the response of two commerciallyimportant CFRP structures to multiple ice impacts. Compos Struct 2011; 2619-2627.

[7] Wen HM. Predicting the penetration and perforation of FRP laminates struck normally by projectiles with different nose shapes. Compos Struct 2000; 49:321-329.

[8] López-Puente J, Zaera R, Navarro C. An analytical model for high velocity impacts on thin CFRPs woven laminates plates. Int J Solids Struct 2007; 44:2837-2851.

[9] Nandlall D, Williams K, Vaziri R. Numerical simulation of the ballistic response of GRP plates. Compos Sci Technol 1998; 58:1463-1469.

[10] Gower HL, Cronin DS, Plumtree A. Ballistic impact response of laminated composite panels. Int J Impact Eng 2008; 35:1000-1008.

[11] López-Puente J, Zaera R, Navarro C. Experimental and numerical analysis of normal and oblique ballistic impacts on thin carbon/epoxy woven laminates. Compos Part A $2008 ; 39: 374-387$ 
[12] Scheffler DR, Zukas JA. Practical aspects of numerical simulation of dynamic events: material interfaces. Int J Impact Eng 2000; 24(8):821-842.

[13] Zukas JA, Scheffler DR. Practical aspects of numerical simulations of dynamic events: effects of meshing. Int J Impact Eng 2000; 24(9):925-945.

[14] Chen JK, Allahdadi FA, Carney TC. High-velocity impact of graphite/epoxy composite laminates. Compos Sci Technol 1997; 57:1369-1379.

[15] Medina DF, Chen JK. Three-dimensional simulations of impact induced damage in composite structures using the parallelized SPH method. Compos Part A 2000; 31:853860.

[16] Shintate K, Sekine H. Numerical simulation of hypervelocity impacts of a projectile on laminated composite plate targets by means of improved SPH method. Compos Part A $2004 ; 35: 683-692$.

[17] Wicklein M, Ryan S, White DM, Clegg RA. Hypervelocity impact on CFRP: testing, material modelling, and numerical simulation. Int J Impact Eng 2008; 35:1861-1869.

[18] Yashiro S, Nakamura T, Ogi K, Yoshimura A. Characterization of high-velocity impact damage in CFRP laminates: Part I- experiment. Compos Part A 2013; 48:93-100.

[19] Randles PW, Libersky LD. Smoothed particle hydrodynamics: Some recent improvements and applications. Comput Meth Appl Mech Eng 1996; 139(1-4):375-408.

[20] Cantwell WJ. The influence of target geometry on the high velocity impact response of CFRP. Compos Struct 1988; 10:247-265.

[21] Hou JP, Petrinic N, Ruiz C, Hallett SR. Prediction of impact damage in composite plates. Compos Sci Technol 2000; 60:273-281.

[22] Toray Industries. Fundamentals of carbon fiber technology and their application to Torayca products. $<$ http://www.torayca.com/en/techref/index.html $>$ [accessed 10.09.12]. 
[23] Miki M, Fukuda T, Motogi S, Hojo M. Composite materials. Tokyo: Kyoritsu Shuppan, 1997 (in Japanese).

[24] Wisnom MR, Häberle J. Prediction of buckling and failure of unidirectional carbon fibre/epoxy struts. Compos Struct 1994; 28:229-239. 


\section{Figure and Table captions}

Fig. 1 Damage states of the front and back surfaces of the impacted specimens. Damage generated on the back surface at $344 \mathrm{~m} / \mathrm{s}$ was barely visible.

Fig. 2 Damage states of the cross-sections (a) normal to the $0^{\circ}$ direction and (b) parallel to the $0^{\circ}$ direction.

Fig. 3 Soft X-ray photographs of the impacted cross-ply specimens.

Fig. 4 Analytical model of the cross-ply laminate considering the symmetry. Interlayer particles were inserted into the ply interface to represent delamination.

Fig. 5 Damage states on the front and back surfaces. Full dimension of the target is depicted considering the symmetry.

Fig. 6 Damage extension in the cross-section beneath the impact point.

Fig. 7 Contribution of shear stresses to damage generation. The color indicates the magnitude of the shear term(s) in Eqs. (3)-(6).

Fig. 8 Projection of the damaged particles. (a) Projected damage area. (b) Delamination at the upper interface. (c) Delamination at the lower interface.

Fig. 9 Schematic of high-velocity impact damage in a cross-ply laminate.

Fig. 10 Comparison of the damage states on the front and back surfaces at $600 \mathrm{~m} / \mathrm{s}$ between the linear elastic analysis and the analysis taking the nonlinear shear into account.

Fig. 11 Comparison of the damage states in the cross-sections beneath the impact point at 600 $\mathrm{m} / \mathrm{s}$ between the linear elastic analysis and the analysis with the nonlinear shear behavior.

Fig. 12 Comparison of the delamination shape at $600 \mathrm{~m} / \mathrm{s}$ between the linear elastic analysis and the analysis with the nonlinear shear behavior. 
Table 1 Material properties of CFRP unidirectional lamina.

Table 2 Material properties of a steel projectile.

Table 3 Material strengths used in this analysis.

Table 4 Degradation rule in material properties and stresses in a broken particle. Superscript $d$ denotes the degraded property. $E_{I}$ is the Young's modulus of the interlaminar layer. 
Table 1

\begin{tabular}{ll}
\hline Density $\rho\left(\mathrm{kg} / \mathrm{m}^{3}\right)$ & $1.6 \times 10^{3}$ \\
Longitudinal Young's modulus $E_{1}(\mathrm{GPa})$ & 139 \\
Transverse Young's modulus $E_{2}(\mathrm{GPa})$ & 9.85 \\
In-plane shear modulus $G_{12}(\mathrm{GPa})$ & 5.25 \\
Out-of-plane shear modulus $G_{23}(\mathrm{GPa})$ & 3.8 \\
In-plane Poisson's ratio $v_{12}$ & 0.25 \\
Out-of-plane Poisson's ratio $v_{23}$ & 0.38 \\
\hline
\end{tabular}


Table 2

\begin{tabular}{ll}
\hline Density $\rho\left(\mathrm{kg} / \mathrm{m}^{3}\right)$ & $7.81 \times 10^{3}$ \\
Shear modulus $G(\mathrm{GPa})$ & 81.0 \\
Sound velocity $c_{0}(\mathrm{~km} / \mathrm{s})$ & 5.33 \\
Parameter of Mie-Grüneisen equation of state $\Gamma$ & 2.0 \\
Parameter of Mie-Grüneisen equation of state $\xi$ & 1.338
\end{tabular}


Table 3

(a) CFRP lamina

Tensile strength in the fiber direction $F_{L t}(\mathrm{MPa})$

Compressive strength in the fiber direction $F_{L c}(\mathrm{MPa})$

Tensile strength in the transverse direction $F_{T t}(\mathrm{MPa})$

Compressive strength in the transverse direction $F_{T_{c}}(\mathrm{MPa}) \quad 248$

Shear strength involving fiber failure $F_{L T f}(\mathrm{MPa}) \quad 450$

In-plane shear strength $F_{L T S}(\mathrm{MPa}) \quad 400$

Out-of-plane shear strength $F_{T T S}(\mathrm{MPa}) \quad 400$

(b) Interlaminar layer

Tensile strength $F_{E t}(\mathrm{MPa}) \quad 90$

Compressive strength $F_{E c}(\mathrm{MPa}) \quad 150$

$\begin{array}{lr}\text { Shear strength } F_{E S}(\mathrm{MPa}) & 50\end{array}$ 
Table 4

Damage mode

Degradation rule

$E_{1}^{d}=0.07 E_{1}$

Fiber tensile failure

$$
\sigma_{11}=\sigma_{22}=\sigma_{33}=\sigma_{23}=\sigma_{31}=\sigma_{12}=0
$$

$E_{1}^{d}=0.14 E_{1}$

Fiber compressive failure

$$
\begin{aligned}
& \sigma_{11}=\sigma_{22}=\sigma_{33}=\sigma_{23}=\sigma_{31}=\sigma_{12}=0 \\
& E_{2}^{d}=0.2 E_{2}, \quad G_{12}^{d}=0.2 G_{12}, \quad G_{23}^{d}=0.2 G_{23}
\end{aligned}
$$

Matrix cracking

Matrix crushing

$$
\begin{aligned}
& \sigma_{22}=\sigma_{12}=0 \\
& E_{2}^{d}=0.4 E_{2}, \quad G_{12}^{d}=0.4 G_{12}, \quad G_{23}^{d}=0.4 G_{23}
\end{aligned}
$$

Delamination

$$
\begin{aligned}
& \sigma_{22}=0 \\
& E_{I}^{d}=0
\end{aligned}
$$

$$
\sigma_{33}=\sigma_{23}=\sigma_{31}=0
$$


$344 \mathrm{~m} / \mathrm{s}$

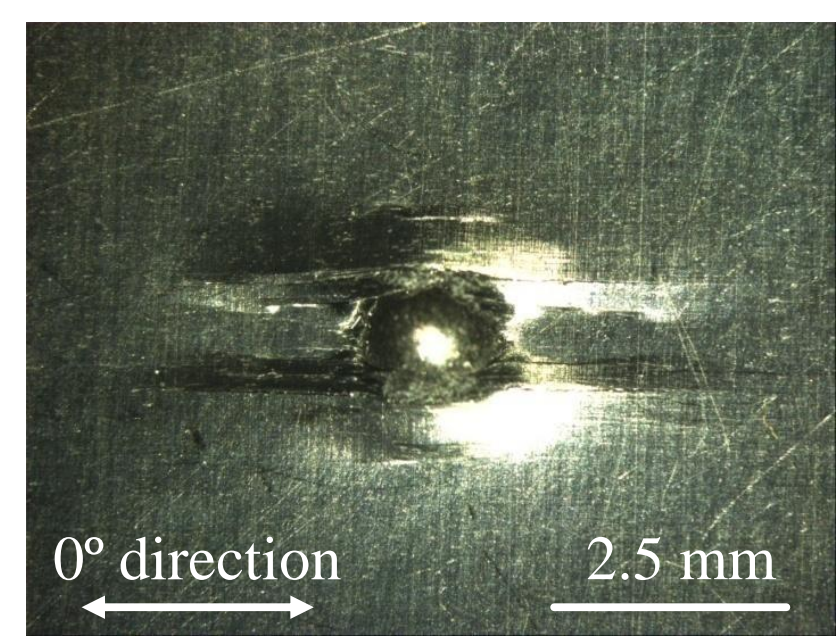

Front

Back
$618 \mathrm{~m} / \mathrm{s}$
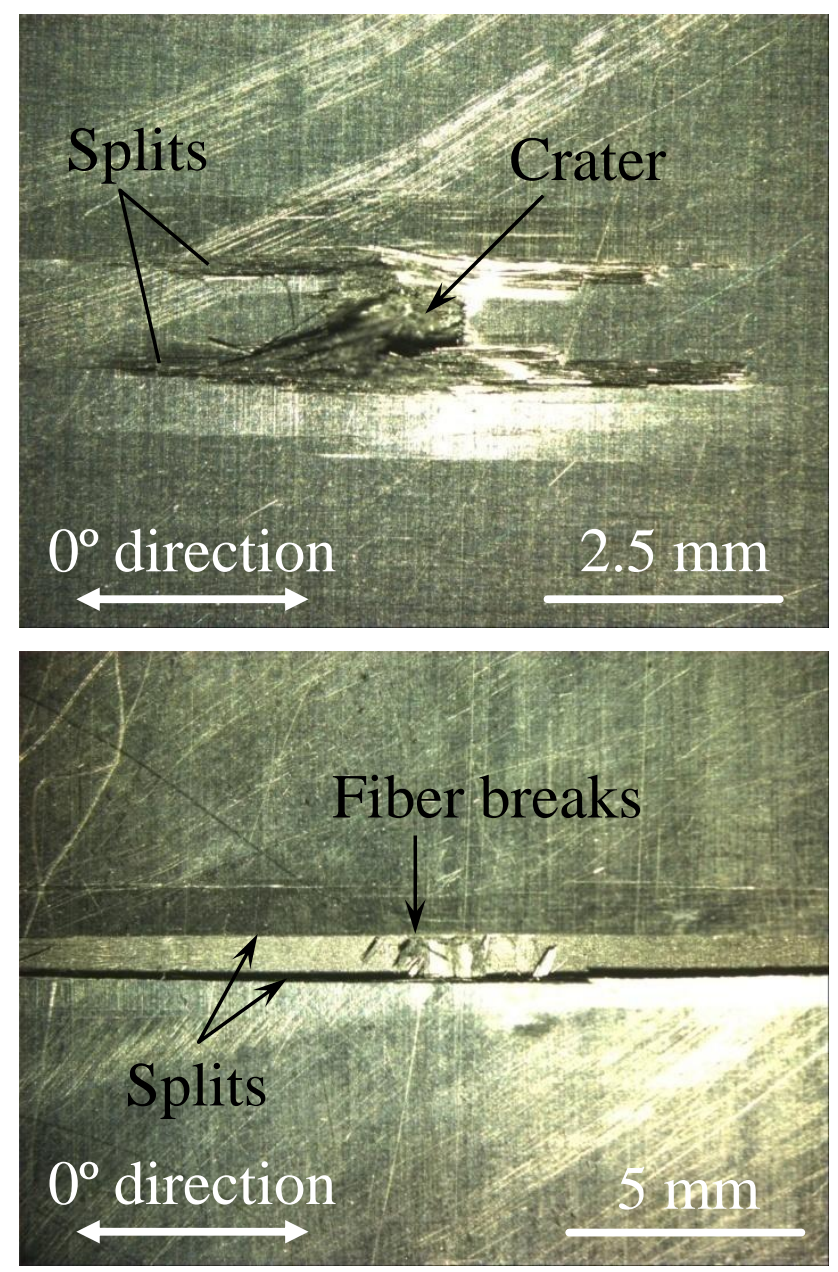

$0^{\circ}$ direction
$885 \mathrm{~m} / \mathrm{s}$
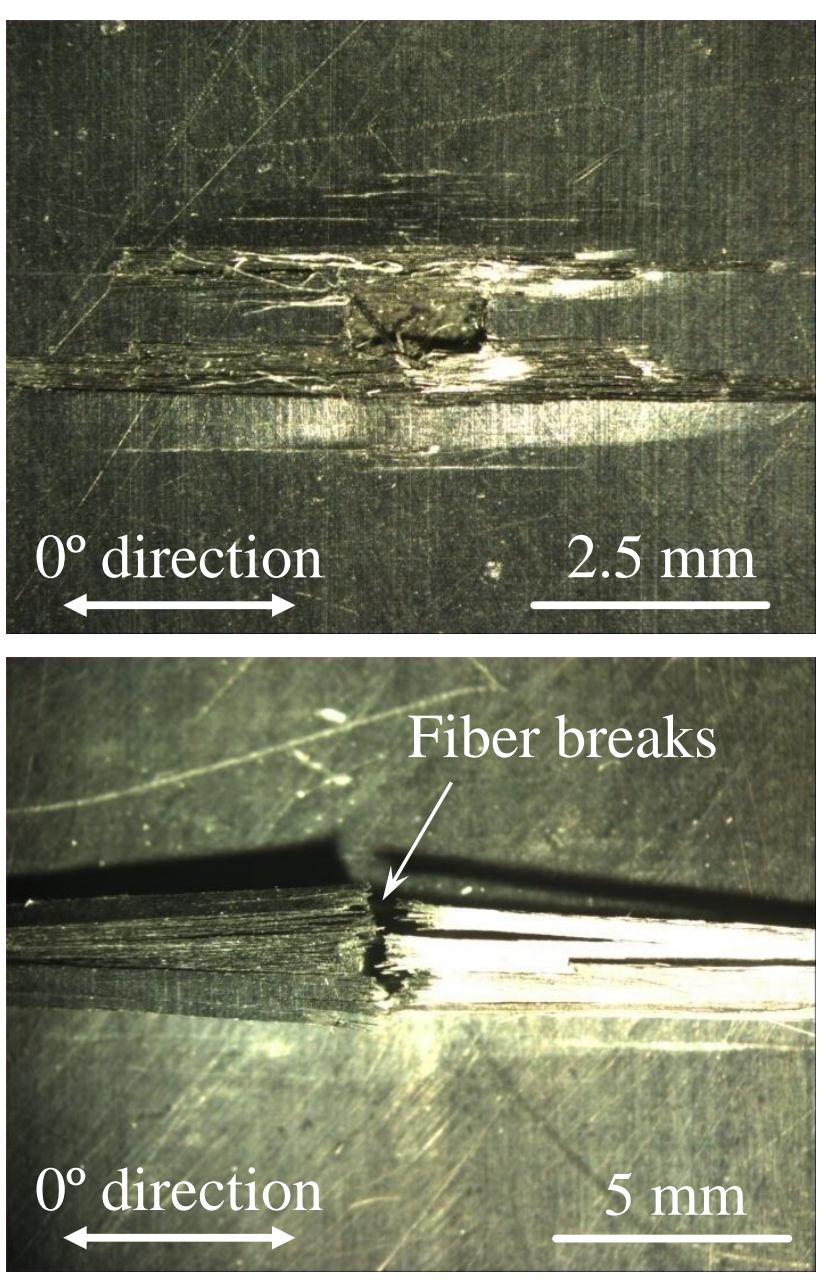

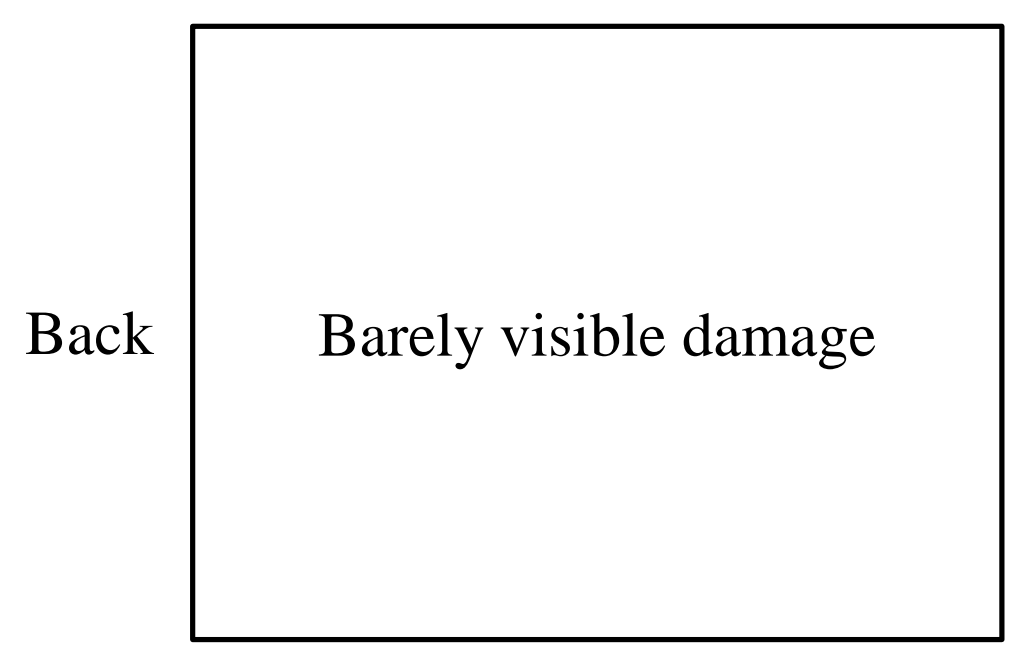




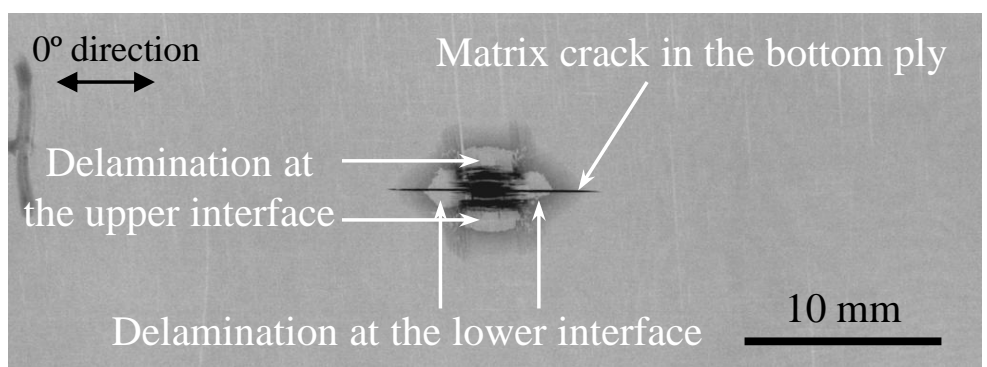

(a) $217 \mathrm{~m} / \mathrm{s}$

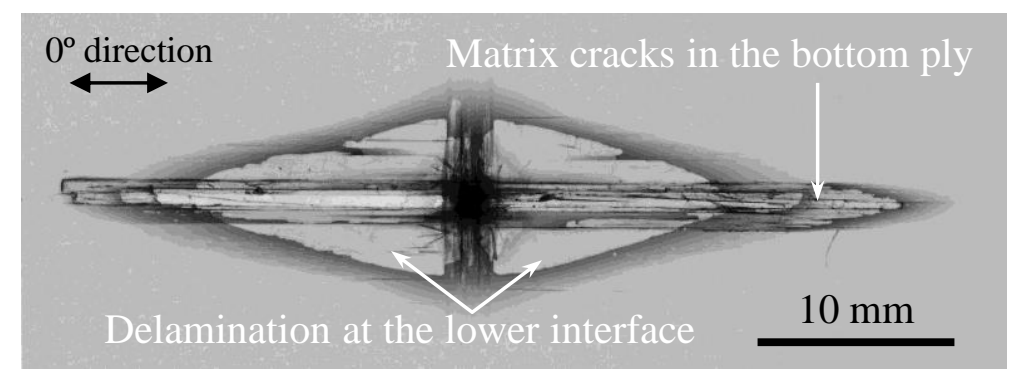

(b) $485 \mathrm{~m} / \mathrm{s}$

Fig. 3 

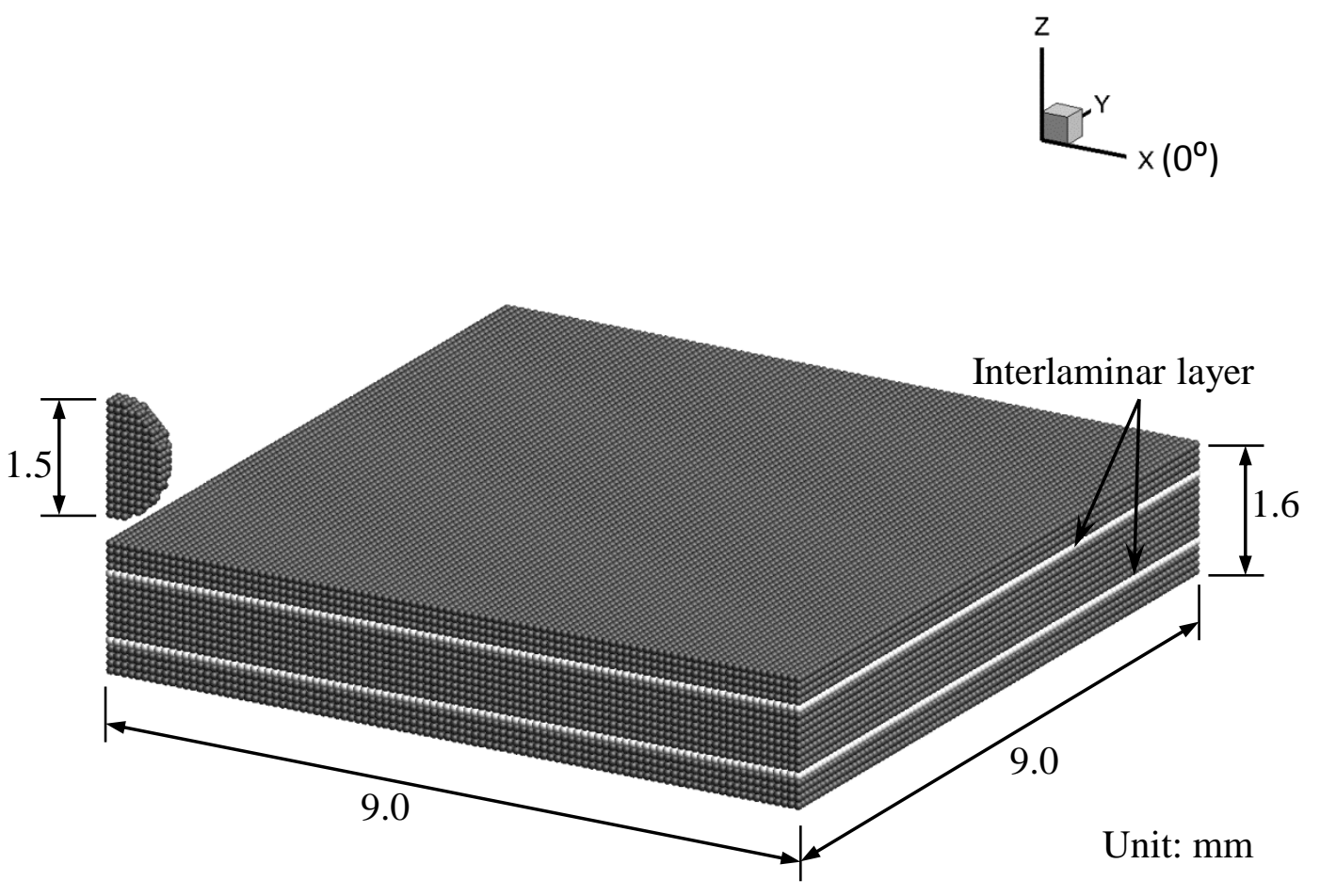

Fig. 4 


\section{Intact Matrix cracking Fiber tensile failure}

Delamination

(A) Matrix failure

$0.4 \mu \mathrm{s} \quad 0^{\circ}$ direction $\bullet$

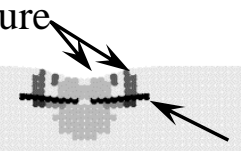

(B) Delamination

$1 \mathrm{~mm}$

$0.8 \mu \mathrm{s}$

(D) Fiber breaks

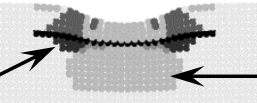

(C) Matrix damage

$2.0 \mu \mathrm{s}$

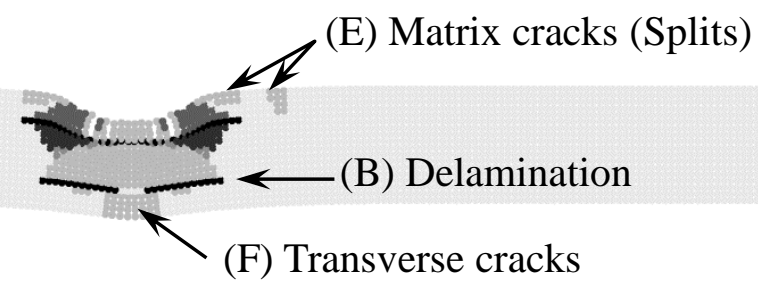

$4.0 \mu \mathrm{s}$

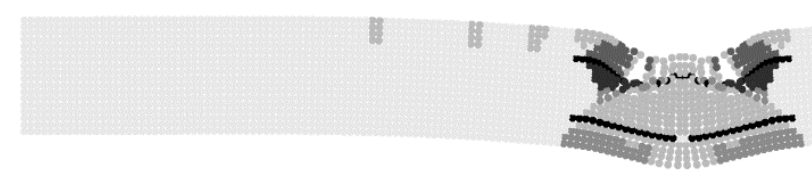

(a) Normal cross-section, $508 \mathrm{~m} / \mathrm{s}$

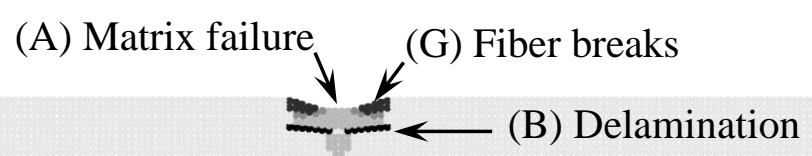

$0.4 \mu \mathrm{s}$

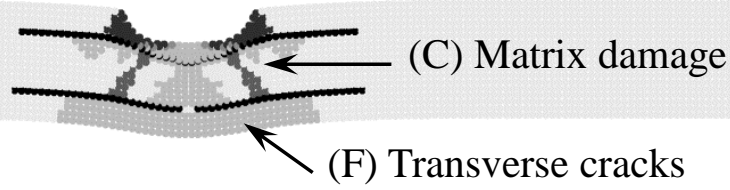

$4.0 \mu \mathrm{s}$

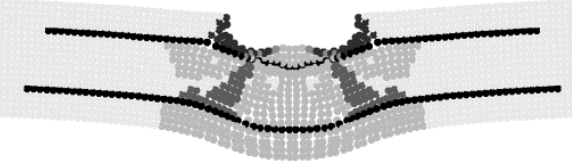

(b) Parallel cross-section, $600 \mathrm{~m} / \mathrm{s}$

Fig. 6 

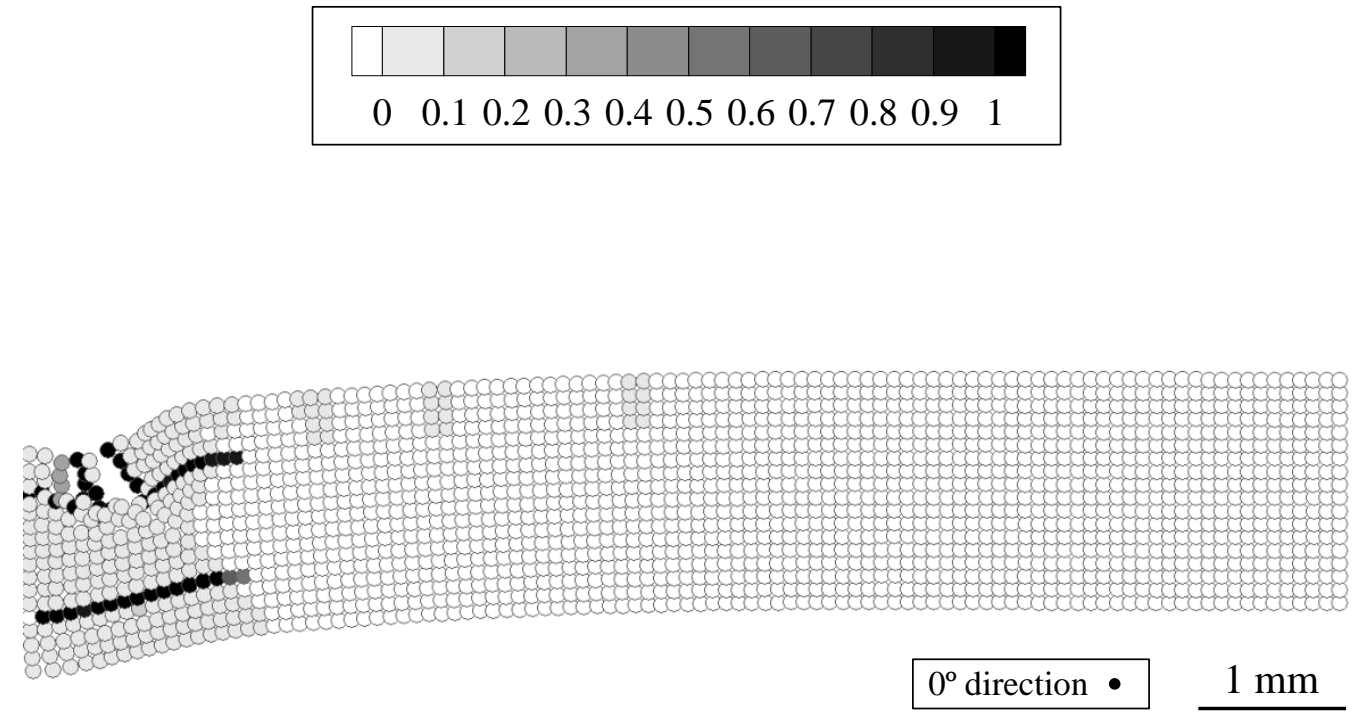

(a) Normal cross-section, $508 \mathrm{~m} / \mathrm{s}$

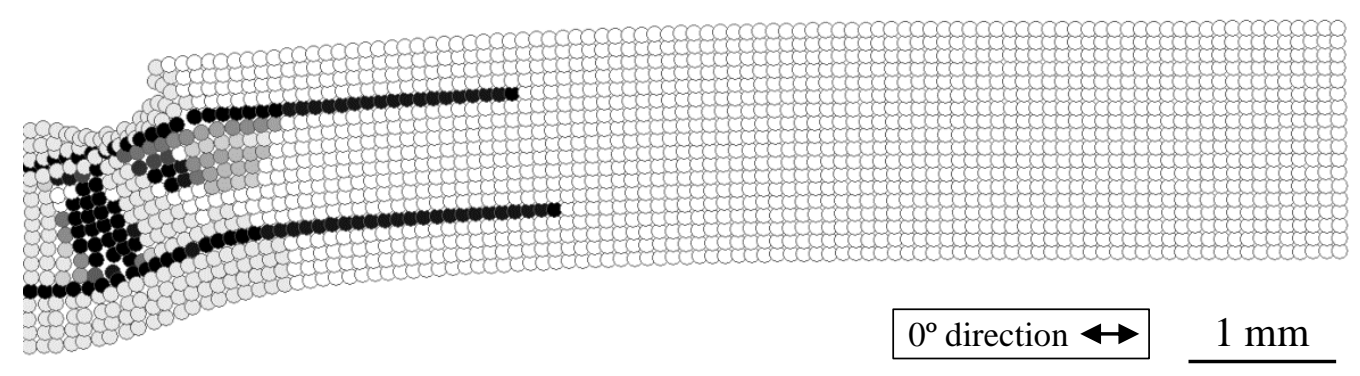

(b) Parallel cross-section, $600 \mathrm{~m} / \mathrm{s}$

Fig. 7 
(F) Matrix crack

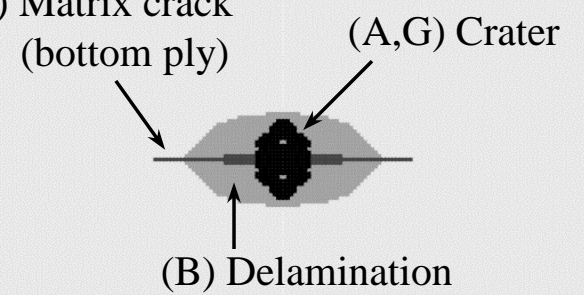

(B) Delamination

(a) $\stackrel{0^{\circ} \text { direction }}{\longleftarrow} \quad$

(b)
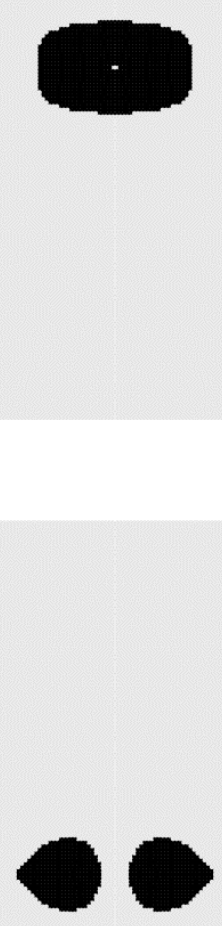

(c)

\section{Fig. 8}



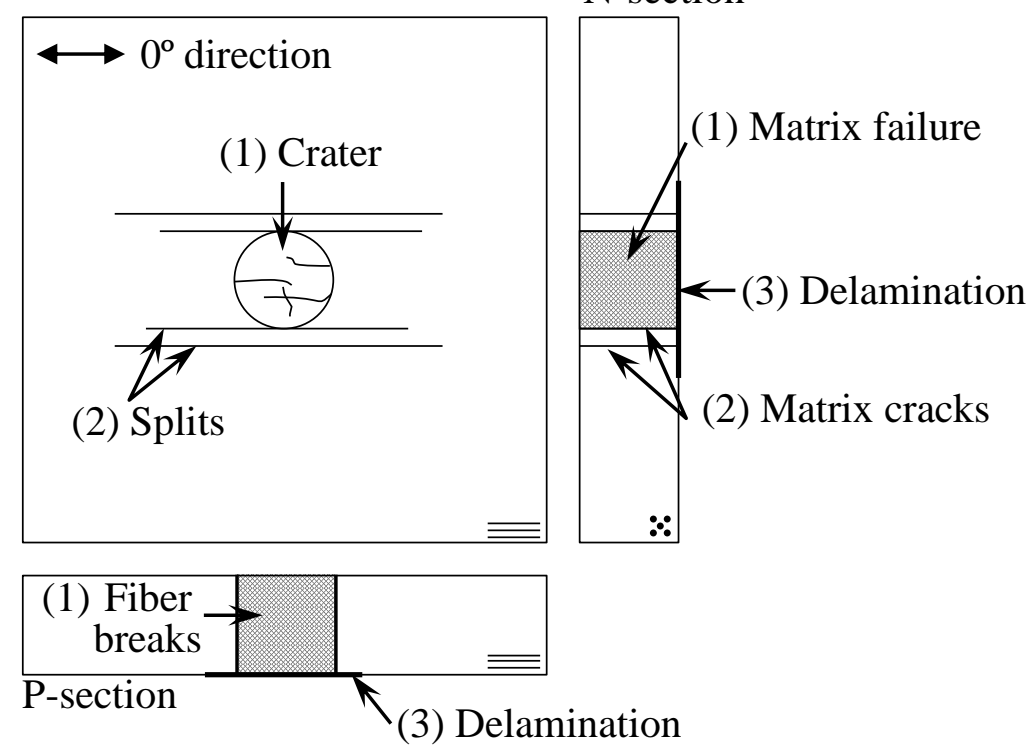

(a) Top $\left(0^{\circ}\right)$ ply
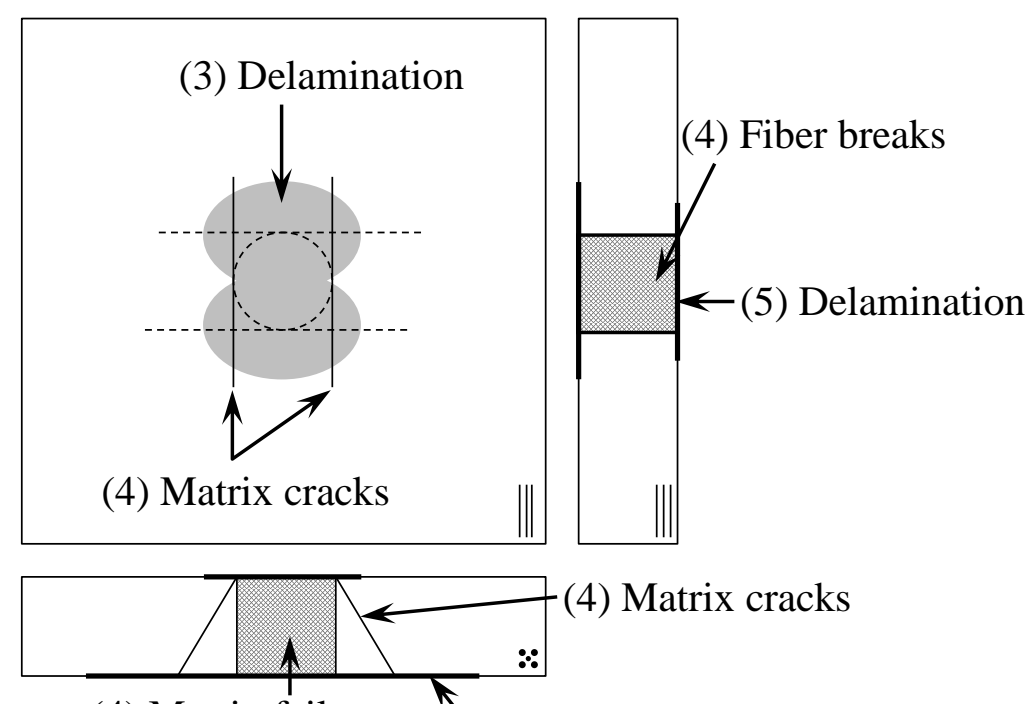

(4) Matrix failure

(5) Delamination

(b) Middle $\left(90^{\circ}\right)$ ply

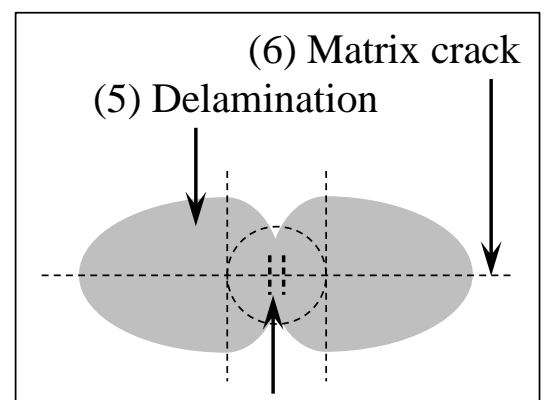

(6) Fiber breaks
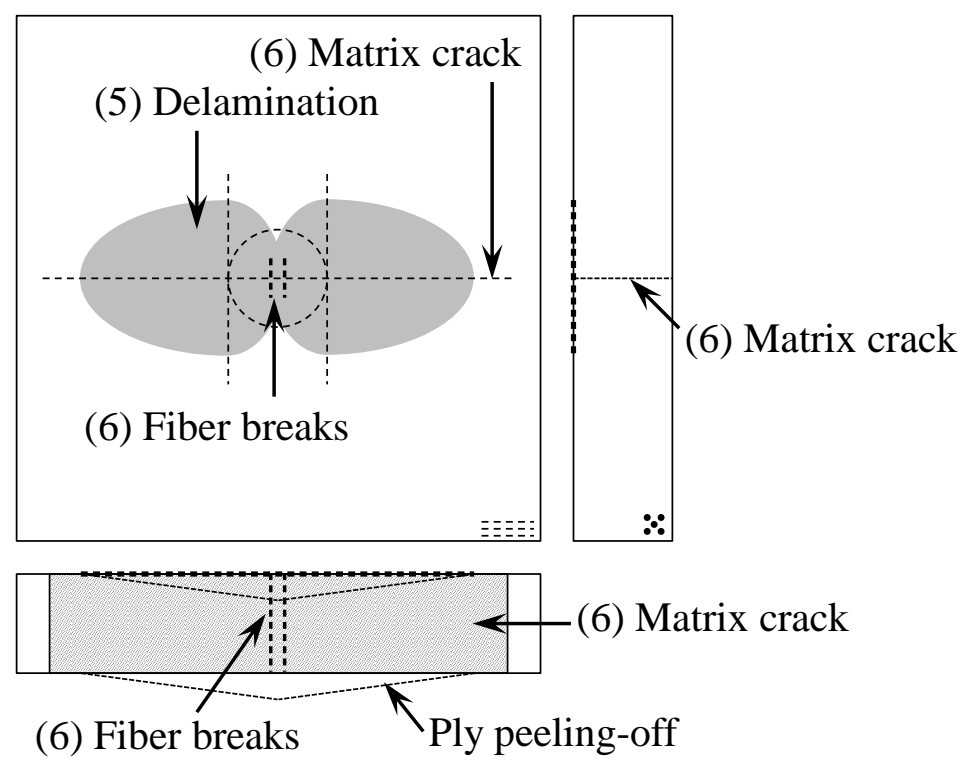

(c) Bottom $\left(0^{\circ}\right)$ ply

\section{Fig. 9}




\begin{tabular}{|l|ll|}
\hline Intact & Matrix cracking & Fiber tensile failure \\
Delamination & Matrix crushing & Fiber compressive failure \\
\hline
\end{tabular}

Linear elastic

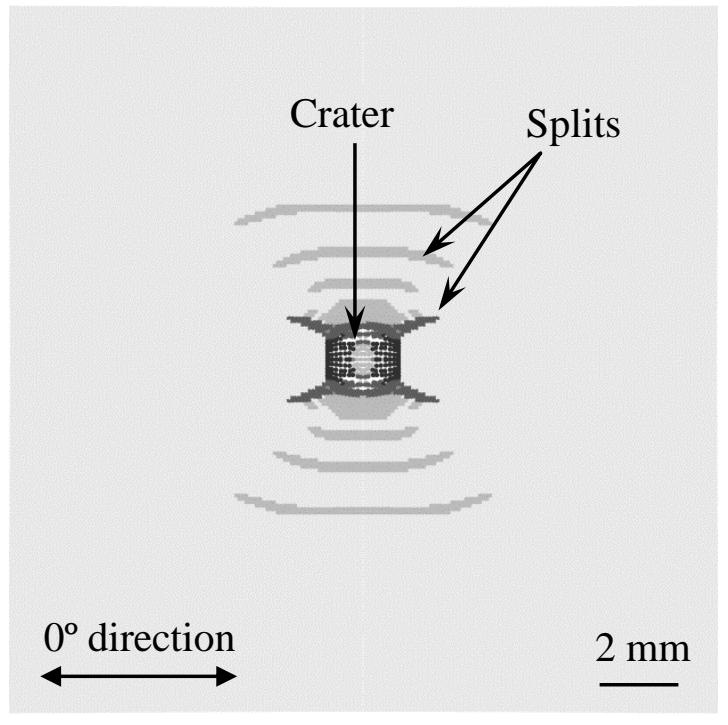

(a) Front surface
With nonlinear shear behavior

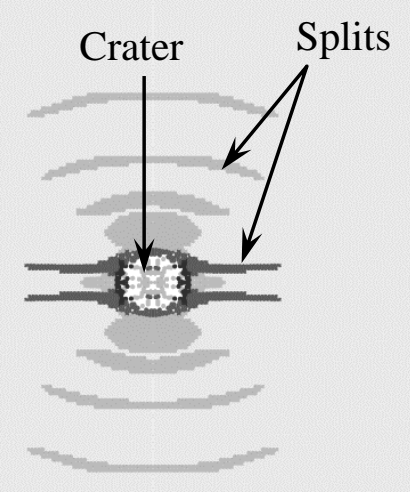

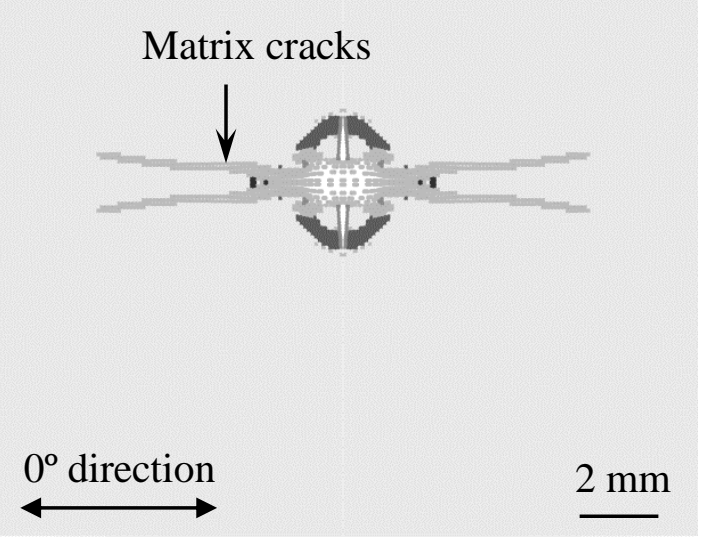

Matrix cracks

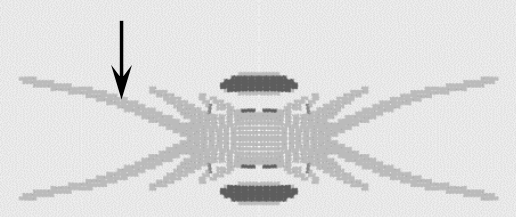

(b) Back surface

Fig. 10 
Linear elastic

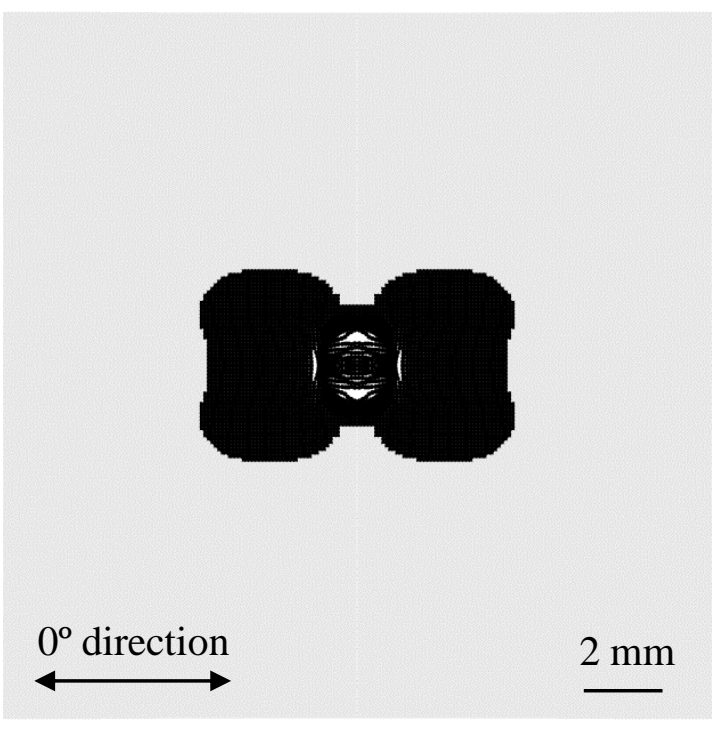

(a) Upper interface
With nonlinear shear behavior

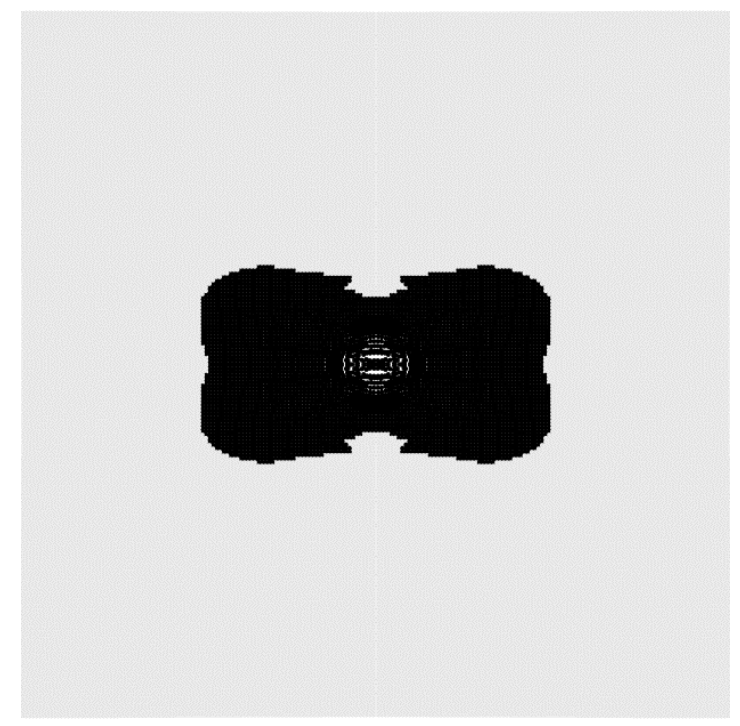

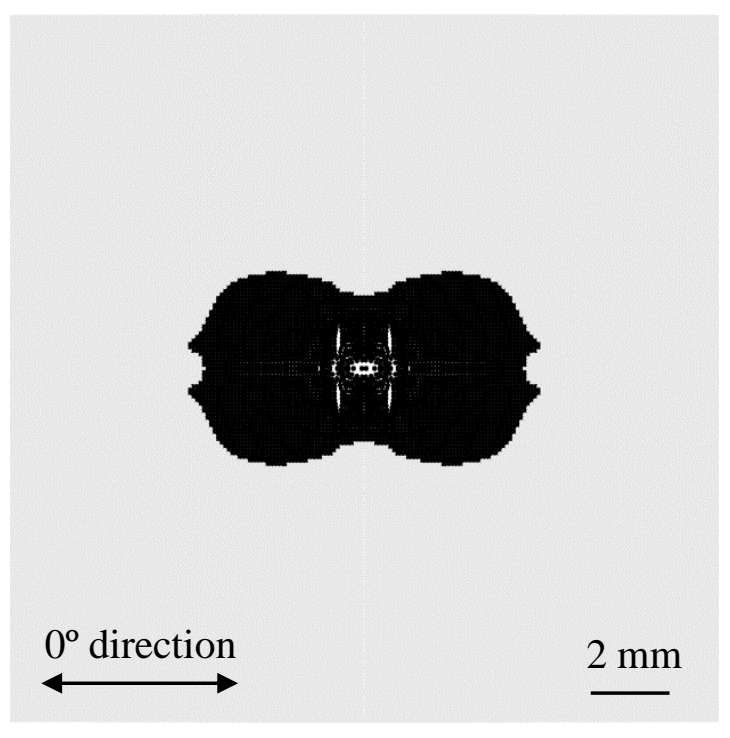

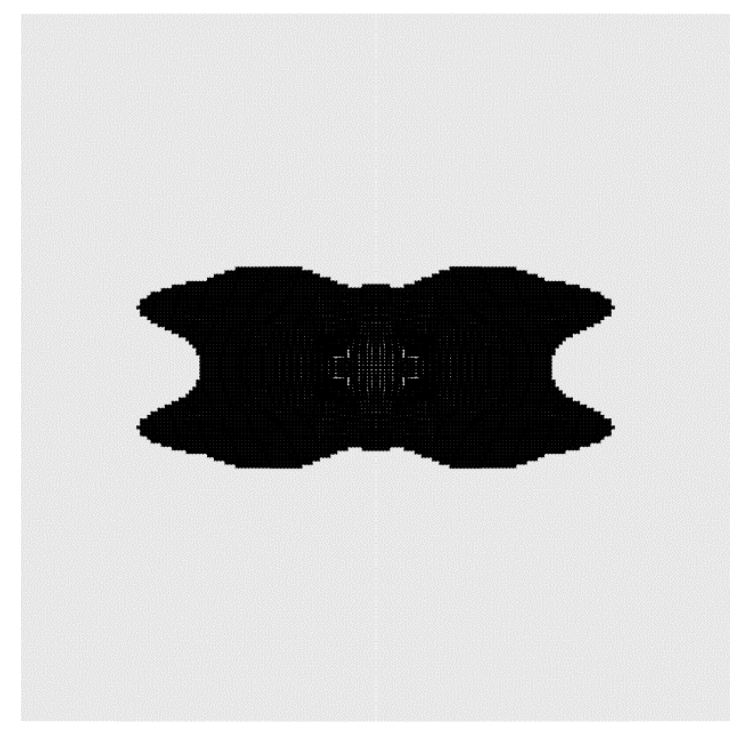

(b) Lower interface

Fig. 12 